\title{
Historia indígena regional: de la investigación a la enseñanza
}

\section{(4) Mirta Zink* \\ Stella Cornelis**}

\section{Resumen}

A partir de la década de 1980,en Argentina se ha producido una significativa renovación en los estudios referidos a las sociedades indígenas, entre ellos de Pampa-Nordpatagonia, que se ha traducido en numerosas publicaciones. No obstante, es preciso preguntarse si esos aportes han impactado en los diseños curriculares en la provincia de La Pampa, en especial en el espacio de Historia. Al mismo tiempo, es necesario observar si esa renovación historiográfica se incorporó en los contenidos de los Planes de Estudio de las carreras de Profesorado y Licenciatura en Historia que se dictan en la Facultad de Ciencias Humanas de la Universidad Nacional de La Pampa (UNLPam), en tanto formadora de futuros docentes. En este artículo se analizan las relaciones entre ese saber académico y su trasmisión a la sociedad, primordialmente a partir del sistema educativo.

\section{Regional indigenous history: from research to teaching}

\begin{abstract}
Since the 1980s, Argentina has witnessed a significant renewal of studies related to the regional indigenous societies, especially those from PampaNordpatagonia, which has resulted in numerous publications. However, it is necessary to ask if these transformations have actually had an impact in the curricular design of La Pampa, specifically regarding History issues. At the same time, it is important to ask if this historiographical transformation has been incorporated into the History degrees curricula at the Facultad de Ciencias Humanas (Faculty of Human Sciences) of the Universidad Nacional de La Pampa (UNLPam), where future teachers are being trained. This paper focuses on the relationship between the academic knowledge and its social comunication, mainly through the educational system.
\end{abstract}

* Instituto de Estudios Socio-Históricos (IESH), Facultad de Ciencias Humanas, Universidad Nacional de La Pampa (UNLPam). Santa Rosa-La Pampa, Argentina. E-mail: mirtazink@gmail.com

** Instituto de Estudios Socio-Históricos (IESH), Facultad de Ciencias Humanas, Universidad Nacional de La Pampa (UNLPam). Santa Rosa-La Pampa, Argentina. E-mail: stellacornelis@yahoo.com.ar
Palabras clave

historia indígena enseñanza

Pampa-Nordpatagonia

Key words

indigenous history teaching Pampa-Nordpatagonia 
1. Una versión preliminar de este trabajo se presentó en el Simposio "Historia indígena y archivos: diversidad, relecturas y experiencias metodológicas", del Segundo Congreso Internacional Los Pueblos Indígenas de América Latina, siglos XIX-XXI. Avances, perspectivas y retos, realizado en Santa Rosa, La Pampa, Argentina, 20 al 24 de septiembre de 2016.

2. La nota completa puede encontrarse on-line. Disponible en Internet: http://www.lanacion.com. ar/193009o-la-utilizacion-populista-de-los-pueblos-originarios. Consultado el 22 de agosto de 2016.

\section{Introducción ${ }^{1}$}

En una nota editorial publicada por el diario argentino La Nación, el 21 de agosto de 2016, titulada "La utilización populista de los pueblos originarios" se critica al "populismo kirchnerista" por el uso que hizo de la historia "para dividir a los argentinos e imponer su falso relato con el solo objetivo de acumular poder para acaparar dinero". El argumento se sustenta en inexactitudes históricas y objetables opiniones cuando señala que Julio A. Roca, en la misa a orillas del río Negro en 1879:

[...] no hubiese podido imaginar que ese emocionante tedeum, muchos años después, iba a ser interpretado como la culminación de una campaña genocida para exterminar a los pueblos originarios de la Patagonia [...] Es perverso intentar una condena moral de quienes representaban en aquel momento la modernidad y el progreso, cuestionando el desplazamiento de otros pobladores, que tampoco estaban desde siempre. Y, mucho menos, para ocupar tierras, ejercer la violencia y demandar indemnizaciones [...] En realidad, se trató de un conflicto de culturas, como ha ocurrido y continuará ocurriendo en toda la historia humana [...] Quienes expandieron la cultura occidental por el territorio de la patria, aun mediante conflictos, sembraron las semillas de un valor esencial que no existía en América [...]: el respeto por la dignidad individual [...], finalmente, plasmado en la concepción moderna de los derechos humanos. ${ }^{2}$

Publicaciones editoriales sin firma de este tenor preocupan, en especial en la actualidad, cuando se dispone de una cuantiosa producción bibliográfica, elaborada por investigadores de distintas universidades nacionales y centros de estudios, quienes desde la década de 1980 han cuestionado las interpretaciones tradicionales y aportado nuevos conocimientos acerca de los procesos sociales, económicos, políticos e ideológicos centrados en las poblaciones indígenas del área pampeana-nordpatagónica. Estos trabajos, que abrevan en perspectivas y enfoques analíticos de la Antropología y la Historia, han complejizado el conocimiento de las parcialidades indígenas y sus relaciones intra e interétnicas, en un área en la cual mantuvieron su autonomía hasta 1880. Paralelamente, las comunidades se han organizado para visibilizar su presencia pública e interpelar la construcción y reproducción de alteridades por diferentes componentes de la sociedad.

Al margen de la intencionalidad política partidaria que tiene la nota, vale preguntarse si los lectores pueden hacer una lectura crítica y contraponer otras explicaciones. En ese sentido, es imprescindible indagar si estamos formando ciudadanos capaces de desmontar estas afirmaciones falaces y descalificadoras acerca de los pueblos originarios.

Este artículo se inscribe en la línea de las investigaciones que abordan el impacto del saber académico fuera de ese ámbito particular, focalizando en este caso en los diferentes niveles del sistema educativo pampeano, con la finalidad de contribuir y complejizar los enfoques que analizan ese objeto de estudio a nivel nacional y en otros contextos. En primer término, este trabajo menciona los aportes realizados desde la UNLPam al conocimiento de la historia indígena regional; en segundo lugar, revisa los contenidos de los Planes de Estudio y Programas de la carrera de Historia que se dicta en la Facultad de Ciencias Humanas de la UNLPam -formadora de futuros docentes; tercero, analiza los diseños curriculares del sistema educativo en la provincia de La Pampa; cuarto, examina contenidos y representaciones en algunos textos destinados a la enseñanza de la historia; quinto, enumera recursos web elaborados para 
la enseñanza de la historia indígena; por último, hay un cierre a modo de conclusión.

\section{Aportes desde la UNLPam a la historia indígena regional}

Con el retorno de la democracia se visibilizaron las demandas de los pueblos originarios, actores sociales que se pretendió ocultar en el proceso de homogenización cultural iniciado a fines del siglo XIX. Así, mediante la reforma constitucional de 1994 se les reconoció su preexistencia étnica y cultural antes de la conformación de los Estados nacionales. Asimismo, los cientistas sociales tuvieron que dar cuenta de esa invisibilización y de los complejos procesos por los cuales una serie de datos fueron seleccionados en función de una determinada política estatal (Delrio, 2012).

La historiografía argentina tradicional construyó el mito de la "Argentina europea" y dejó a los nativos en el pasado, tras la gesta "heroica" de la lucha contra el indio, que se justificó como una guerra entre "civilización" y barbarie". Las explicaciones, en muchos casos con informaciones dudosas, se redujeron a juicios de valor ante el "enemigo" que asolaba la frontera y representaba un obstáculo para el "progreso" de la nación.

Una visión diferente surgió en las últimas décadas del siglo XX, cuando algunos investigadores se abocaron a estudiar a las sociedades indígenas y sus relaciones con los hispano-criollos con nuevos abordajes teóricos, metodológicos y fuentes. En esa tarea fue fundamental combinar los aportes de la Historia, la Antropología y la Arqueología, ampliar la escala de análisis espacial, romper los límites de las historias nacionalistas y provinciales, para dar paso a la emergencia de múltiples y complejas relaciones intragrupales e interétnicas previas a la constitución de los Estados nacionales. Así, nuevos mundos en el nuevo mundo esperaban ser restituidos en los acontecimientos históricos americanos, como también una mirada crítica al avance de las fronteras interiores, a las terribles consecuencias para los vencidos y las políticas estatales de invisibilización de los sobrevivientes. ${ }^{3}$

En ese contexto se enmarcan los estudios en la Facultad de Ciencias Humanas de la UNLPam con la reincorporación de docentes que habían sido cesanteados, entre ellos Daniel Villar -docente al mismo tiempo de la Universidad Nacional del Sur-. Así, se iniciaron proyectos de investigación que tuvieron como protagonistas a las sociedades indígenas de Pampa, Nordpatagonia, la zona cisandina y trascordillerana. Inicialmente, a partir de la relectura etnohistórica de fuentes editas y después con la incorporación de documentos provenientes de diferentes archivos y repositorios, tarea que se complementó con la publicación de fuentes inéditas. En ese marco se redactaron ponencias, artículos, libros, ${ }^{4}$ se organizaron seminarios, eventos académicos y se formaron nuevos investigadores/as.

El fundador del Instituto de Estudios Regionales, Julio Colombato, también cuestionó la idea de "desierto" y la desaparición de los indígenas después del avance final de la frontera. Desde ese espacio, en 1997 se comenzó a editar Quinto Sol. Revista de Historia Regional, bajo la dirección de Villar y en su primer número incluyó dos artículos -de cuatro en total- referidos a las poblaciones indígenas regionales. Esta temática mantuvo su vigencia en volúmenes posteriores y en 2007 se publicó un número destinado exclusivamente al estudio del pasado y presente de las poblaciones indígenas de Pampa y Nordpatagonia, ${ }^{5}$
3. Respecto al desarrollo y avances en las investigaciones históricas de los pueblos indígenas de pampa y patagonia, remitimos a Mandrini (2007), Salomón Tarquini y Casali (2015).
4. Algunas de las publicaciones fueron: Di Liscia y Zink (1995), Villar (1997, 1998), Villar y Zink (1998), Di Liscia (1999), Altube (1999), Salomón Tarquini (2001), Zink (2002), Di Liscia (2002a y 2002b), Villar (2003), Salomón Tarquini y Zink (2004), Salomón Tarquini (2006), Salomón Tarquini y Abbona (2010); para un listado exhaustivo ver Salomón Tarquini (2015).

5. La colección completa de la revista está on-line. Disponible en Internet: http://cerac.unlpam.edu.ar/ index.php/quintosol/issue/archive. 
6. El IESH se creó en 2001 y fue continuación del anterior.

7. Disponible en Internet: https:// corpusarchivos.revues.org
8. Los capítulos iniciales de estas publicaciones abordan el poblamiento indígena previo a la fundación de las localidades centenarias. Al respecto consultar Salomón Tarquini y Zink (2008 y 2009); Berón (2009); Depetris (2009); Zink y Günther (2011); Salomón Tarquini y Dillon (2011); Rollhauser (2011); Salomón Tarquini y Del Río (2014).

9. Esa publicación de 2008 -ampliada- se reeditó en 2014 y contiene: el poblamiento inicial de La Pampa según los principales sitios arqueológicos (Zink, 2014), texto revisado por Mónica Berón y Alicia Tapia; las sociedades indígenas y las relaciones sociales en espacios de frontera (Zink y Salomón Tarquini, 2014) y el repoblamiento indígena: $1880-1950$ (Salomón Tarquini, 2014). como resultado del Primer Encuentro de Investigadores y Pueblos Originarios que se realizó el año anterior en la UNLPam, co-organizado por el Instituto de Estudios Socio-Históricos (IESH) ${ }^{6}$ e integrantes de distintas agrupaciones indígenas nucleadas en la Federación India del Centro de Argentina, promovida por Germán Canhué.

A mediados del año 2000, se formó otro grupo de investigación, dirigido por Axel Lazzari, que se abocó al estudio de las "identidades" en torno a la pampeanidad y contempló a los grupos indígenas. Estos estudios continuaron fundamentalmente en campos disciplinares de la Historia, la Antropología y la Lingüística, en vinculación con otras instituciones. En ese contexto, surgió luego la revista digital Corpus. Archivos virtuales de la alteridad americana, ${ }^{7}$ editada por varias universidades.

Los períodos de estudio y las temáticas se ampliaron y diversificaron, comprendiendo desde el siglo XVIII hasta el siglo XXI, y a las relaciones interétnicas y fronterizas se sumaron problemáticas vinculadas a la integración de los indígenas a la sociedad nacional, la re-emergencia étnica, la interculturalidad, las discusiones acerca del pasado y los derechos indígenas. Paralelamente, se incorporaron diferentes tipos de fuentes, tales como informes y expedientes sobre tierras, prensa, diarios personales, correspondencia, legajos catastrales, cartografía, fotografías, memorias de sacerdotes salesianos, registros electorales, eclesiásticos y militares, testimonios orales, registros fílmicos y documentos de las comunidades. Desde el aspecto metodológico, al análisis de fuentes documentales se sumaron procesamientos cuantitativos y trabajos de campo a través de la observación participante (Salomón Tarquini, 2015).

Desde la extensión universitaria también se concretaron varias actividades que tuvieron como eje a las poblaciones originarias, una de ellas es la elaboración de libros históricos de los pueblos, en varios casos en el marco del centenario de su fundación, una ocasión propicia para desarrollar iniciativas tendientes a la construcción de la identidad colectiva en clave local. En este emprendimiento -que aún sigue vigente- participaron además investigadores extrauniversitarios y vecinos y dio como resultado la elaboración de varios libros que contienen capítulos referidos a los primeros pobladores y a los pueblos originarios, con el fin de desterrar la idea de "desierto", la eliminación de los indígenas con el avance final de la frontera y otras concepciones estereotipadas y etnocéntricas respecto a estas parcialidades. ${ }^{8}$

Otra de las acciones tuvo como propósito dar respuesta a un reclamo de la comunidad: la elaboración de una obra que sistematizara las investigaciones que se venían realizando dentro y fuera de la Universidad; es decir, un material actualizado de la historia de La Pampa. De esta manera, se concretó un proyecto multidisciplinario en el marco de Áreas Prioritarias de la Universidad con el fin de producir insumos para la capacitación de recursos humanos. Se elaboraron notas de divulgación, micros radiales y, finalmente, en 2008 se editó un extenso tomo con un recorrido que se inicia con el poblamiento de la zona -ca. 8000 AP- y culmina en1952 con la provincialización del Territorio Nacional. En este volumen hay capítulos destinados a las sociedades indígenas, las relaciones en espacios de frontera y el repoblamiento indígena. ${ }^{9}$ La publicación tuvo como destinatario al público en general y, en particular, a los docentes de los distintos niveles educativos y a los estudiantes de los cursos superiores.

Al mismo tiempo, se desarrollaron distintas acciones desde el Departamento de Investigaciones Culturales del Archivo Histórico Provincial, cuyas varias 
publicaciones refieren a las poblaciones indígenas. ${ }^{10}$ Entre ellas, Memorias de las Jornadas Ranquelinas (Poduje, 1998) y Presencia ranquelina, una compilación a cargo de María Inés Poduje (2001) a partir del trabajo realizado con un grupo de jóvenes de ascendencia ranquelina del oeste pampeano. No podemos finalizar este somero detalle sin mencionar la labor realizada de manera independiente por José Carlos Depetris (2003), quien se abocó al análisis genealógico de numerosos pobladores pampeanos que, en muchos casos, desconocían o negaban su ascendencia indígena. Su contribución fue pionera en visibilizar esta pervivencia, aun cuando historiadores locales reproducían la idea de la eliminación tras la "conquista del desierto".

\section{Los planes de estudio en la carrera de Historia}

En 1998 en el ámbito universitario se abrió el debate interclaustros con el objetivo de reformar el Plan de Estudio de la carrera de Historia en la Facultad de Ciencias Humanas de la UNLPam. Se argumentó la antigüedad del Plan vigente que databa de 1984, la necesidad de incluir los cambios operados en el campo de la historiografía y las Ciencias Sociales, el diseño de estrategias destinadas a superar la distancia habitual entre formación disciplinar, teóricopedagógica y práctica docente. Esa discusión culminó al año siguiente con una serie de cambios, ${ }^{11}$ entre ellos, la inclusión del Seminario de Historia Indígena Regional en el Profesorado, que en gran medida fue impulsada por algunos estudiantes vinculados a proyectos de investigación relacionados a esta temática; si bien ese espacio quedó como optativo con el Seminario de Historia de Asia, África y Oceanía.

Entre las competencias del egresado, en el Plan de 1999 se mencionó el conocimiento de las vinculaciones de los procesos sociales básicos de la historia mundial, americana y argentina con la historia regional. En ese marco, la temática indígena regional se incluyó en los contenidos mínimos del espacio curricular Historia Argentina I, al abordar las sociedades indígenas y las relaciones interétnicas entre la etapa colonial y mediados del siglo XIX; pero no sucedió lo mismo en las siguientes Historias Argentinas (II y III). Respecto a las Historias Americanas, la primera comprendía la etapa prehispánica, la segunda se centraba en la organización del espacio colonial y las menciones a las poblaciones indígenas eran con relación a ese proceso conquistador, mientras que en la tercera se vinculaban con la era republicana. En el área de la formación avanzada, el Seminario de Investigación en Historia Regional incorporó el estudio de las parcialidades indígenas regionales en el siglo XIX y se ofrecía como opción el Seminario de Historia Indígena Regional, que a partir de conceptos, enfoques y métodos antropológicos e históricos proponía abordar esta problemática entre los siglos XVI y XIX (Resolución CS-UNLPam $N^{\circ}$ 079/99). Esta estructura se mantenía en la Licenciatura, porque había un tronco común compartido (Resolución CS-UNLPam N 064/99).

En 2009 se reabrió el debate para adecuar los Planes a los cambios producidos en el sistema educativo argentino, como consecuencia de la implementación de la Ley 26.206/06 de Educación Nacional. Las principales modificaciones se centraron en eliminar algunas materias de la formación docente -que se había incrementado en el Plan de 1999- y en reemplazar otras por espacios orientados a la formación disciplinar. ${ }^{12}$

En esa oportunidad, por presión de un grupo de estudiantes -apoyados implícitamente por un sector docente- se eliminó la opción explícita del Seminario
10. La nómina de las publicaciones se puede consultar on-line. Disponible en Internet: https:// sitio.lapampa.edu.ar/index. php/investigaciones-culturales/ publicaciones

11. Esa modificación fue sustancial respecto al Plan de 1983 , se incorporó una asignatura introductoria de Antropología y se priorizaron los procesos históricos de la segunda mitad del siglo XX en el orden mundial, americano y argentino, con la creación de nuevas cátedras y el desdoblamiento de contenidos.

12. En esa ocasión se suscitó un duro enfrentamiento con el Departamento de Formación Docente, porque desde las carreras de Historia, Letras y Geografía se planteó la necesidad de recuperar espacios curriculares disciplinares. En el Plan de la carrera de Historia, la puja finalizó con la eliminación de dos asignaturas pedagógicas y la sustitución de otras tres por Didáctica Especial, Metodología de la Investigación Histórica y Epistemología e Historia. En compensación, se incluyó un eje transversal en las materias disciplinares orientado a preparar a los estudiantes para una incorporación progresiva en distintos contextos socio-educativos y superar la distancia habitual que existe entre formación disciplinar y pedagógica. 
13. Las divisiones cronológicas son: Historia Argentina I, 1776-1880, Historia Argentina II, 1880-1945 e Historia Argentina III 1945-2003.

14. Este Seminario abarca de fines del siglo XIX a la segunda mitad del $\mathrm{XX}$.

15. Depetris y Vigne (2000), Lluch (2002), Mases (2002), Argeri (2005), Delrio (2005), Salomón Tarquini (2010), entre otros. de Historia Indígena Regional del Profesorado y se mantuvo como optativo con Historia del Arte en la Licenciatura; aunque en la fundamentación del nuevo Plan se consignó que las modificaciones respondían a la necesidad de contemplar los cambios producidos en el campo de la historiografía y las Ciencias Sociales, que alientan a combinar los enfoques de las diversas disciplinas sociales con la Historia. El debate fue arduo, en parte se personalizó la discusión y desde el sector estudiantil que participó activamente se esgrimió que había otros colectivos y problemáticas que también debían contemplarse. Respecto a la historia indígena, señalaron que se podía incluir en las Historias Americanas, Argentinas y en el Seminario de Investigación en Historia Regional, una propuesta impulsada por un sector docente. Así, en Historia de América II se incorporó como contenido amplio la postergación de los pueblos originarios, mientras que en Historia Argentina I se reemplazó la mención a las sociedades indígenas por la problemática de la frontera, que ahora se extendía hasta 1880 al variar los cortes temporales vigentes, ${ }^{13}$ y en Historia Argentina II se agregó el avance final de la frontera, sin referencias a los grupos derrotados. En tanto, el Seminario de Investigación en Historia Regional $^{14}$ agregó contenidos y bibliografía relacionada a la pérdida de la autonomía y la incorporación al Estado nacional (Resoluciones CS- UNLPam $\mathrm{N}^{\circ} 228 / 09$ y N 194/11).

Si realizamos una lectura de los programas vigentes en busca de una especificidad temática acerca de las sociedades indígenas de Pampa-Nordpatagonia, zona cisandina y trascordillerana, en Historia de América II se menciona la invasión europea en el continente americano en el área rioplatense y Chile, sin embargo, sólo se nombra como bibliografía teórica el texto de Ana María Lorandi, Sudamérica Oriental, publicado por Trotta en el vol. II de 2000. En Historia Argentina I se consigna como contenido las relaciones interétnicas y se cita el capítulo del mundo indígena en vísperas de la invasión europea del libro La Argentina aborigen, de Raúl Mandrini, editado en 2008 por Siglo XXI. En otra unidad se menciona como tema especial la frontera y las relaciones interétnicas y se indica en la bibliografía de consulta el artículo de Silvia Ratto titulado "¿Soberanos, clientes o vecinos? Algunas consideraciones sobre la condición de los indígenas en la sociedad bonaerense", de 2003, publicado en el libro Conflicto, poder y justicia en la frontera bonaerense, 1818-1832; y otro de Susan Socolow de 1987 "Los cautivos españoles en las sociedades indígenas: el contacto cultural a través de la frontera argentina", publicado en el Anuario IEHS. El Seminario de Investigación en Historia Regional contempla a las sociedades indígenas regionales en el siglo XIX, las relaciones sociales en espacios de frontera, los itinerarios y resistencias indígenas; centra el listado bibliográfico en los acontecimientos posteriores al avance final de la frontera. ${ }^{15}$ El Seminario Optativo de Historia Indígena Regional contempla el estudio de las sociedades indígenas regionales y las relaciones interétnicas en un amplio espacio que incluye Pampa-Nordpatagonia-Cordillera-Araucanía partir del siglo XVIII, en un contexto fronterizo de fricción con sociedades estatales. También se analiza la incorporación al Estado mediante la implementación de políticas de destribalización, proletarización, traslados masivos, invisibilización y criminalización de prácticas culturales.

Cuando se debatió la exclusión de este último espacio curricular, se acordó que esta temática se incorporaría en los contenidos de las asignaturas de Historia Argentina y en el Seminario de Investigación en Historia Regional -materia en la que más se visibiliza-. Sin embargo, en general esa inclusión se vincula sobre todo a la problemática de la frontera y el accionar estatal; por ende, la dinámica particular de los procesos históricos indígenas se diluye. Paradójicamente, en 
la región que hoy ocupa la provincia de La Pampa las distintas parcialidades mantuvieron su autonomía e interacción con la sociedad colonial y luego republicana durante tres siglos. Raúl Mandrini (2007) ha señalado que el estudio de las sociedades originarias es un tema que en general no interesa al grueso de los historiadores en nuestro país, si bien reconoce los avances en ese sentido.

La estructura de cátedras -en lugar de áreas temáticas- y las designaciones docentes acorde a ese esquema, no facilita la enseñanza de contenidos acorde a la formación específica de cada profesor/a. No obstante, consideramos que pervive una connotación eurocéntrica en la selección del conocimiento y la enseñanza de la historia en Latinoamérica, tal como sostienen Robert Aman (2010) y Manuel Pousa Castelo (2013). Enrique Dussel (1992) señala que Europa se autoafirmó como el centro de la historia mundial y sus hechos se impusieron hacia otras partes, algo "se da" en el mundo Occidental para expandirse al resto. Esa perspectiva del conocimiento, elaborada en la primera mitad del siglo XVII, como expresa Aníbal Quijano (2000), se asoció a la secularización burguesa del pensamiento europeo y a las necesidades y experiencias del patrón mundial de poder capitalista, colonial y eurocentrado. Así, en las representaciones que se derivan existe una incapacidad de percibir la identidad humana de los otros, de reconocerlos a la vez como iguales y como diferentes.

\section{Las currículas escolares}

En 1987, el Estado provincial se planteó realizar cambios en los lineamientos curriculares de la escuela media y se elaboró un diagnóstico con opiniones de distintos actores sociales. Luego, se constituyó una Comisión Curricular integrada por representantes del gobierno y del gremio docente con la finalidad de redactar un Proyecto de Cambio en el Secundario, a partir de cuatro pilares organizadores: desformalización de los vínculos interpersonales, regionalización, integración y flexibilización y actualización de contenidos. Estos puntos se trabajaron en talleres y se plasmaron en los nuevos lineamientos curriculares en 1990. A partir de allí se inició el diseño de los contenidos disciplinares, en el contexto de la transferencia de los servicios educativos nacionales a las provincias y de la creación de numerosos establecimientos secundarios dependientes de la órbita provincial. ${ }^{16}$

En el caso de Historia, uno de los propósitos era recuperar la intencionalidad que se la atribuía a la historia a comienzos de la década de 1970: lograr que fuera un factor de transformación, a partir del conocimiento detallado de la realidad en la cual el individuo estaba inserto. ${ }^{17}$ En consecuencia, en el primer año del secundario la currícula se iniciaba con la historia de la localidad y la provincia para proyectarse a las dimensiones nacional, latinoamericana y mundial en los cursos siguientes. Los contenidos comenzaban con el estudio de las sociedades indígenas y de las relaciones interétnicas fronterizas antes del avance final de la frontera. Uno de los principales desafíos fue la búsqueda de información y la elaboración de material didáctico, porque las nuevas investigaciones históricas referidas a la región tenían aún escaso desarrollo. No obstante, los docentes elaboraron algunas propuestas novedosas.

Este Proyecto quedó trunco con la sanción de la Ley Federal de Educación de 1993, porque La Pampa fue pionera en la implementación de esa normativa. De ese modo, la centralidad de la historia local y regional se diluyó en los contenidos proyectados para el tercer ciclo de la Educación General Básica (EGB) y el nivel Polimodal en esta jurisdicción, al igual que la especificidad de
16. En 1982 existían ocho colegios secundarios dependientes de la jurisdicción provincial, entre 1985 y 1991 se crearon diecisiete establecimientos (Billorou y Sánchez, 2011:143). A partir del $1^{\circ}$ de enero de 1992, se transfirieron a las provincias y a la Municipalidad de la Ciudad de Buenos Aires los servicios educativos administrados en forma directa por el Ministerio de Cultura y Educación y por el Consejo Nacional de Educación Técnica, Ley $N^{\circ} 24.049$ (Disponible en Internet: http://servicios.infoleg.gob.ar/ infoleglnternet/anexos/o-4999/448/ norma.htm. Consultado el 13 de agosto de 2016).

17. Lo regional se concebía como lo más cercano y conocido en el tiempo y espacio, un concepto dinámico que se debía actualizar partiendo de los códigos socioculturales propios de cada sector y comunidad, para que sean protagonistas en la regionalización de los contenidos. Ver Proyecto de Cambio en la Educación Media (1990). 
18. Ver Diseño Curricular EGB 2 (1999).

19. Ver Materiales Curriculares Tercer Ciclo EGB. Ciencias Sociales (1997). Materiales curriculares para el Nivel Polimodal. Historia I y II (2001)

20. Ver Materiales Curriculares para la Educación Primaria-Ciencias Sociales (2015). las disciplinas dentro del campo de las Ciencias Sociales. Esa ley estableció la obligatoriedad del tercer ciclo y la formación optativa para el siguiente nivel; con ese cambio se fragmentó la educación secundaria y los resultados fueron deficientes y negativos en muchos aspectos.

Los procesos históricos regionales, que incluían a las sociedades indígenas, se explicitaron en los diseños curriculares del segundo ciclo de la EGB. En $4^{\circ}$ año la propuesta era analizar la "organización y transformación del espacio local por la población nativa" y en $5^{\circ}$ año la "ocupación, organización y transformación del espacio provincial y regional por la población aborigen. Prehistoria americana: pueblos que habitaron el territorio pampeano. Modos de vida: aspecto económico-cultural-social y político". ${ }^{18}$

Para el tercer ciclo de la EGB, en el área de Ciencias Sociales, el eje específico de Historia, denominado "Las sociedades a través del tiempo", no contemplaba contenidos sobre las poblaciones indígenas previo a la conquista; sólo había una única referencia para Historia de $8^{\circ}$ año cuando se mencionaban las creencias y la religión en el mundo indígena, al analizar la vida en las sociedades de América colonial (siglos XVI al XVIII). En el nivel Polimodal no se explicitaron contenidos vinculados al mundo indígena; Historia I se articuló en torno a la conformación y consolidación del sistema capitalista mundial entre 1750-2000, e Historia II en torno a la génesis y consolidación del Estado argentino. ${ }^{19}$

En la actualidad, rige la Ley de Educación Nacional № 26.206 (2006) que establece en sus artículos el respeto por la multiculturalidad y el conocimiento de las culturas originarias, para valorar y comprender la diversidad cultural y los derechos de los pueblos indígenas (artículos 54 y 92). Además, incorpora la Educación Intercultural Bilingüe (EIB) como modalidad para los niveles inicial, primaria y secundaria, con el objeto de garantizar el derecho constitucional de los pueblos indígenas a recibir una educación que contribuya a preservar y fortalecer sus pautas culturales, su lengua, su cosmovisión e identidad étnica; a desempeñarse activamente en un mundo multicultural y a mejorar su calidad de vida (artículo 52).

En los materiales curriculares para la educación primaria, elaborados por equipos técnicos del Ministerio de Cultura y Educación del Gobierno de La Pampa, se contemplan para el área de Ciencias Sociales diversas referencias a los pueblos indígenas. ${ }^{20}$

En segundo grado se propone: “Reconocer en la cultura de las sociedades indígenas, sus conflictos y luchas en el pasado y en el presente a partir de la valoración y visibilización de las mismas" (p. 35).

En cuarto grado:

Comparar las diversas organizaciones territoriales de la Argentina y La Pampa a lo largo de la historia, teniendo en consideración cómo se modificó la configuración territorial en las distintas etapas (época colonial, etapa independiente, etapa indígena, etapa territoriana, actualidad, entre otras). Se sugiere trabajar a partir de la comparación de distintas cartografías (p. 42).

Reconocer la existencia de diferentes sociedades en el actual territorio argentino y pampeano a partir de diferenciar sociedades cazadoras-recolectoras de sociedades sedentarias-agricultoras (p. 46). 
Enfatizar la presencia de sociedades preexistentes en el actual territorio de la provincia de La Pampa antes de la llegada de los europeos a América, a partir del reconocimiento de diversas y sucesivas etapas de poblamiento indígena (p. 46).

Identificar los actores que intervinieron en el proceso de conquista, sus motivaciones, sus intereses y los modos de hacerlos prevalecer. Se sugiere analizar desde las concepciones y definiciones que los europeos difundieron de los indígenas, hasta las diversas formas de trabajo forzoso que subordinaron a los diferentes pueblos indígenas (p. 47).

Conocer las diferentes respuestas de las sociedades indígenas americanas ante los intentos de los españoles por someterlas a su dominio, y la comparación entre distintos procesos de conquista. Se sugiere trabajar las rebeliones indígenas (p. 47).

Reconocer las relaciones entre los pueblos originarios de diferentes regiones. Por ejemplo, las relaciones entre los actuales territorios de La Pampa y Patagonia (p. 46).

A continuación, el documento curricular menciona que esos objetivos suponen una serie de acciones y habilidades para aportar a la construcción de una conciencia crítica respecto de los procesos de conquista, del pasado y su continuidad en el presente, a partir de contrastar la visión del "descubrimiento" y del "encuentro" con el de "conquista" (págs. 46 y 47).

Finalmente, para quinto grado menciona:

Conocer y explicar las relaciones que se establecieron entre la sociedad criolla y las sociedades indígenas, a través de analizar las zonas de fronteras como áreas no solo de conflictos sino también como espacios de intercambios económicos y culturales, por ejemplo la frontera bonaerense (p. 55).

Identificar y comprender las políticas estatales implementadas como la "conquista" de las tierras indígenas para expandir la frontera productiva, el fomento a la inmigración ultramarina para atraer trabajadores y la inversión de capitales extranjeros para insertarse en el mercado mundial (p. 62).

Estos objetivos son sumamente ambiciosos para el nivel educativo primario y contemplan una serie de abordajes teóricos y metodológicos complejos que requieren ser profundizados en la instancia escolar siguiente, también de carácter obligatoria. Sin embargo, en los diseños curriculares para el nivel secundario se advierte una menor presencia de temáticas relacionadas con los pueblos originarios. Así, en $2^{\circ}$ año del ciclo básico uno de los ejes estructurantes refiere a "las sociedades indígenas americanas, la producción de excedentes y la distribución de bienes materiales y culturales" (p. 10). La sugerencia de los autores del documento es que se compare una sociedad imperial con una no imperial. Otro eje se vincula con la conquista de esas sociedades por los europeos, el impacto que tuvo la misma y las formas de resistencias-alianzas que establecieron con los conquistadores.

En $3^{\circ}$ año, se prevé abordar la construcción y consolidación del Estado argentino a fines del siglo XIX, en el marco de la expansión capitalista y de la división internacional del trabajo. El documento del Ministerio de Cultura y Educación señala que esto supone conocer la construcción del Estado y la comprensión del marco jurídico-institucional, para relacionar ese proceso con 
21. Ver Materiales Curriculares para el primero, segundo y tercer año del Ciclo Básico de la Educación Secundaria: Historia (2009).

22. Los NAP son el resultado de acuerdos curriculares entre el $\mathrm{Mi}$ nisterio de Educación nacional y las jurisdicciones provinciales, con el objetivo de darle unidad al sistema educativo en el país. Ver Núcleos de Aprendizajes Prioritarios. Ciclo Básico Educación Secundaria $1^{\circ}$ y $2^{\circ} / 2^{\circ}$ y $3^{\circ}$ Años (2011).
23. Ver Materiales Curriculares para el cuarto y quinto año del Ciclo Orientado de la Educación Secundaria: Historia (2013). Materiales Curriculares para el Ciclo Orientado de la Educación Secundaria: Antropología (2013). Materiales Curriculares para el sexto año del Ciclo Orientado de la Educación Secundaria: Historia (2013).

24. Las orientaciones son: Agrario, Artes Visuales, Arte (Danza, Música, Teatro), Ciencias Naturales, Ciencias Sociales y Humanidades, Comunicación, Economía y Administración, Educación Física, Informática, Lenguas y Turismo. Resolución № 1272, Boletín Oficial de la Provincia de La Pampa № 3014, 14 de septiembre de 2012 .

25. Ver Marcos de Referencia Educación Secundaria Orientada, Bachiller en Arte (2011). Bachiller en Lengua (2011), Bachiller en Turismo (2011). las transformaciones ocurridas a partir de la inserción en el mercado internacional, el análisis de los movimientos y conflictos sociales y políticos. Finalmente, plantea la incorporación del Territorio Nacional de La Pampa a la expansión agraria a través del estudio de la construcción política, social y económica del territorio. En ese marco, no hay ninguna referencia explícita a la presencia indígena en la región ni a las consecuencias que tuvo para estas sociedades el avance final de la frontera. ${ }^{21}$

Complementan esta normativa los Núcleos de Aprendizaje Prioritarios (NAP) $1^{\circ}$ y $2^{\circ}, 2^{\circ}$ y $3^{\circ}$ año del Ciclo Básico de la educación secundaria. ${ }^{22}$ Entre los contenidos para $1^{\mathrm{er}}$ año señalan:
El análisis de las formas de organización de las sociedades indígenas americanas en relación con la organización de los trabajos, la distribución del excedente, la jerarquización social, la legitimación a través del culto y de los sistemas de creencias, a partir del tratamiento de uno o dos casos
[y]
La comprensión de los procesos de conquista y colonización europea en América desde múltiples interpretaciones, enfatizando en el impacto sobre las sociedades indígenas y en las variadas relaciones (resistencias, cooptaciones, alianzas) que éstas establecieron con los conquistadores (p. 18).

Los casos que en general se seleccionan son del área Mesoamericana y Andina (aztecas/mexicas e incas), porque figuran en los textos escolares y facilitan la tarea docente.

En el ciclo orientado ${ }^{23}$ de la educación secundaria cada una de las orientaciones ${ }^{24}$ presenta una estructura curricular diferenciada, con materias de formación general y formación específica. La asignatura Historia se ubica dentro del primer grupo y la carga horaria asignada a la misma varía en función de la orientación. Así, Historia I y II están previstas para $4^{\circ}$ y $5^{\circ}$ año de todas las modalidades, excepto para aquellos estudiantes que cursen las orientaciones de Ciencias Naturales y Economía y Administración, que tienen la materia en $5^{\underline{0}}$ y $6^{\underline{0}}$ año. Además, Historia III se contempla como parte de la formación específica de Ciencias Sociales y Humanidades y Turismo.

En los materiales curriculares para este último tramo del secundario hay escasas referencias específicas a la temática indígena. Solo para $6^{\circ}$ año de las orientaciones Ciencias Sociales y Humanidades y Turismo se indica como objetivo general "analizar demandas y protestas sociales a partir de nuevas organizaciones y actores sociales" (p. 22), en el listado de temas sugeridos figura la cuestión indígena actual. En la primera modalidad figura la asignatura Antropología y el eje de estudio es la otredad y la conformación de identidades, ahí se incluye la cuestión indígena; pero queda limitada a los estudiantes que optan por Ciencias Sociales y Humanidades.

En los NAP de la formación general del Ciclo Orientado no hay alusiones a las sociedades indígenas. En los Marcos de Referencia para cada orientación se mencionan los pueblos originarios y sus expresiones musicales, la perspectiva plurilingüe e intercultural para la enseñanza de las lenguas y las iniciativas de turismo social-solidario-comunitario relacionadas con experiencias asociadas a pueblos originarios. ${ }^{25}$ 


\section{Textos destinados a la enseñanza de la historia}

Si nos remontamos a la etapa territoriana, advertimos que la preocupación de las autoridades por construir un relato histórico sobre el pasado se visualizó claramente a fines de la década de 1930, durante el mandato del gobernador Miguel Duval (1941). Su inquietud primordial era mostrar el grado de progreso y "civilización" que se había alcanzado tras la denominada "conquista del desierto", superando así la etapa indígena. Uno de los indicadores era precisamente el "desarrollo cultural" y, en especial, el conocimiento de la historia y geografía pampeana, motivo por el cual apoyó las actividades del novel Centro de Estudios Pampeanos, presidido por Enrique Stieben, quien cobró trascendencia como "historiador oficial".

Este intelectual redactó numerosas notas acerca de la historia del Territorio ${ }^{26}$ y en 1946 publicó el libro La Pampa, su historia, su geografía, su realidad y su porvenir, texto que tuvo una amplia y prolongada inserción en las aulas. En esa construcción histórica enfatizó la "gesta gloriosa" de quienes lucharon contra la "barbarie indígena", contrapuso la imagen del araucano bravo y guerrero a la mansedumbre de los indios "autóctonos". Entre estos últimos mencionó a los ranqueles y los describió como bárbaros holgazanes del caldenar, tan inútiles que ni siquiera sabían criar la poca hacienda que consumían; remarcó la presencia visible de esta parcialidad hasta mediados del siglo XX (Stieben, 1946). Un denominador común en sus relatos fue el triunfo del "progreso", gracias al tesón de los inmigrantes europeos por sobre las adversidades del territorio "virgen". También esta "historia oficial" estaba en consonancia con el proyecto nacional de "argentinizar" la heterogénea composición social.

Muchos años más tarde, en 1986, el Ministerio de Cultura y Educación provincial editó una colección destinada a los establecimientos educativos. Una de las publicaciones se tituló La Pampa Total. Aspectos históricos, tomos I y II, ${ }^{27}$ era básicamente una enumeración de acontecimientos ordenados cronológicamente: etapa prehistórica, ocupación indígena, avance de la frontera, fundación pueblos, acción político-administrativa yobras hasta la provincialización (1951). Con posterioridad, no se imprimieron obras relativas a la historia de La Pampa hasta 2008, cuando la Universidad publicó el tomo de Historia de La Pampa citado anteriormente, con el auspicio del gobierno provincial. Este libro -corregido y ampliado en 2014- está destinado a un amplio público y, en especial, a docentes de distintos niveles educativos, brinda nuevos contenidos y actualiza otros en un extenso período en base a las investigaciones más recientes.

Un texto que se elaboró específicamente para los alumnos, y está vigente en las aulas, fue Activa. La Pampa para el área de Ciencias Sociales de $4^{\circ}$ grado del nivel primario, editado por Puerto de Palos (AA.VV., 2002). Los autores -profesora y licenciado en Historia- incorporaron algunos aspectos renovadores con relación a la historiografía tradicional aunque, al mismo tiempo, incluyeron conceptos como "complejo ecuestre" y "araucanización" sin problematizarlos, además de explicaciones inherentes a la organización económica y social de las poblaciones nativas que fueron cuestionadas por las investigaciones posdictadura militar. El libro no contiene referencias bibliográficas.

En los niveles superiores -secundario-se utilizan los textos escolares de circulación nacional que, en general, remiten a aztecas, incas y mayas cuando se refieren a América antes de la conquista. Algunos libros mencionan a los pueblos que habitaron el actual territorio argentino, los describen a partir de
26. Stieben fue docente y dirigente socialista en la década de 1920 , luego su derrotero político lo acercó estrechamente a Duval. Tuvo vinculaciones con ámbitos académicos nacionales. Entre las publicaciones que realizó se destacan notas en el diario santarroseño La Capital, conferencias radiales emitidas por $\mathrm{LR}_{1}$ Radio “El Mundo" (Stieben, 1940), un artículo en la revista Gloriosa Nación -de circulación nacional- en el número especial dedicado a La Pampa.

27. Las autoras, Norma Benítez, Violeta Diez y Milna Marini de Díaz Zorita eran profesoras y licenciadas en Historia del nivel secundario, además ejercieron la docencia universitaria hasta mediados de la década de 1980. 
28. Un ejemplo es la propuesta de la editorial Santillana (Mérega et al., 2010), que incorpora los reclamos actuales como el acceso a la tierra, la educación intercultural bilingüe, entre otros, y el surgimiento de los movimientos indianistas.

29. Algunos contenidos son: Pueblos originarios que habitan en Argentina (Disponible en Internet: http://www.educ.ar/sitios/educar/ recursos/ver?id=71029). Diversidad cultural y reconocimiento de las lenguas originarias (Disponible en Internet: http://www.educ.ar/sitios/ educar/recursos/ver?id=15146\& $\mathrm{re}$ ferente $=$ docentes). Las voces del silencio: La esperanza y lucha de los pueblos aborígenes en la actualidad (Disponible en Internet: http://www.educ.ar/sitios/educar/ recursos/ver?id $=90585 \&$ referente =docentes), Breve historia de los pueblos aborígenes en la Argentina (Disponible en Internet: http:// www.educ.ar/sitios/educar/recursos/ver?id $=91827 \&$ referente $=$ doce ntes), Los derechos de los pueblos originarios (Disponible en Internet: http://www.educ.ar/sitios/educar/ recursos $/$ ver?id $=92164$ \& referente $=$ docentes).

30. Se puede consultar Con nuestra voz, una serie de textos plurilingües escritos en castellano y en lenguas indígenas con miembros de pueblos originarios de todo el país (Disponible en Internet: http://eib. educ.ar/2015/11/con-nuestra-voztextos-plurilingues.html), el libro Pueblos indígenas y estado: Aportes para una reflexión crítica en el aula, videos animados y enlaces vinculados a estas temáticas (Disponible en Internet: http://eib.educ.ar/).

31. Disponible en Internet: http://www.mapaeducativo. edu.ar/pueblos_indigenas/ index.php? option= com content\&view $=$ article\&id $=16$

32. Disponible en Internet: http://www.fundacionluminis. org.ar/recurso-didactico-online/ indigenas-la-argentina-viaje-artela-cultura-los-pueblos-originariosserie-6-audiovisuales

33. Disponible en Internet: https://www.youtube.com/ watch?v=ZellwyiyH 7 s

34. Disponible en Internet: https:// pueblosoriginariosargentina. wordpress.com/ su localización geográfica -Cuyo, Norte, Centro, entre otras- y los clasifican según sus pautas de movilidad: nómades, seminómades y sedentarios, desde una concepción estática. Asimismo, a veces aún aluden a la superioridad de la cultura blanca cuando tratan la conquista de América. Otro aspecto son las escasas o ausentes referencias a los indígenas a partir de la conformación del Estado nacional, producto de las políticas de invisibilización (Nagy, 2013). Las resistencias a la dominación, la incorporación subordinada de las poblaciones nativas, la emergencia y problemáticas de los pueblos originarios en el presente son contenidos que algunas editoriales han incluido en los textos escolares en los últimos años. ${ }^{28}$ Este tímido avance en publicaciones de circulación nacional contrasta con las prescripciones curriculares de los NAP, que se mencionaron anteriormente (Lewkowicz y Rodríguez, 2015).

En una mirada de larga duración se observa que el tratamiento de las sociedades indígenas, la conquista de América y la emergencia de los pueblos originarios se ha complejizado; en especial, en las propuestas editoriales que han incorporado en el equipo autoral a investigadores del campo antropológico (Lewkowicz, 2015). Sin embargo, resta profundizar la historicidad de los distintos grupos indígenas, desterrar representaciones estereotipadas, actualizar información y dar cuenta de la situación actual de las comunidades.

\section{Recursos web para la enseñanza de la historia indígena}

Además de los libros, se crearon páginas web con variados recursos relacionados a la historia indígena, este formato facilita la actualización, difusión, circulación y uso educativo. Estas producciones, en su mayoría, ofrecen nuevas miradas y perspectivas. A modo ilustrativo, no exhaustivo, se pueden mencionar los sitios Educar ${ }^{29}$ y Educación Intercultural Bilingü̈ ${ }^{30}$ del Ministerio de Educación y Deportes de la Nación, que contienen numerosas propuestas y actividades para la enseñanza de variados aspectos referidos a las sociedades indígenas. Otro recurso interesante es el Atlas de pueblos indígenas, en donde es posible encontrar documentos, fuentes históricas, bibliografía, documentales y un mapa de pueblos indígenas. ${ }^{31}$ Asimismo, la fundación Lúminis presenta Indigenas de la Argentina: Un viaje por el arte y la cultura de los pueblos originarios con seis audiovisuales de distintas regiones argentinas. ${ }^{32}$

En La Pampa desde el IESH se presentó un Proyecto de Voluntariado a la Secretaría de Políticas Universitarias, en el marco de una convocatoria del Bicentenario de la Revolución de Mayo. El resultado fue la realización, en conjunto con el canal de la Cooperativa Popular de Electricidad de Santa Rosa, de seis documentales de Historia de La Pampa. El primero está destinado a los primeros pobladores y el segundo a las sociedades indígenas regionales. ${ }^{33}$ Asimismo, en el Seminario de Historia Indígena Regional se diseñó la página web Pueblos originarios: recursos para el aula, que contiene un listado de libros, fascículos, sitios web, películas, videos y documentales, acompañados de una ficha crítica respecto al contenido y su empleo con fines didácticos. ${ }^{34}$

En 2016, otra iniciativa que se concretó en la UNLPam fue el Proyecto de Extensión Universitaria Nuevos caminos para la EIB: hacia el rescate de las voces ranqueles desde del libro a las nuevas tecnologías. Este proyecto registró en audio y en lengua ranquel las lecciones de la publicación impresa Curso de Ranquel, que luego se socializaron en la página web http//www.humanas.unlpam.edu. ar/wordpress/eib. Además del manual bilingüe tiene actividades didácticas e interactivas, fuentes documentales, material bibliográfico, audiovisuales, 
fotografías y textos que facilitan el conocimiento de la lengua, historia, cultura y cosmovisión de los ranqueles. En estas acciones intervinieron instituciones educativas, gubernamentales y miembros de la comunidad ranquel (Fernández Garay et al., 2016). ${ }^{35}$

En el ámbito del Ministerio de Cultura y Educación provincial se creó el repositorio Recursos Educativos Pampeanos, para enriquecer los procesos de enseñanza y aprendizaje de los contenidos curriculares. Incluye material audiovisual, sonoro y documental relacionado con las sociedades indígenas, tales como la muestra Primeros Pintores Pampeanos, una exposición realizada en 1997 en el marco del Programa Documentación y Preservación del Arte Rupestre Argentino (INAPL), ${ }^{36}$ el video La Pampa. Viaje a través de su tiempo y su espacio, que comienza con el poblamiento indígena; ${ }^{37}$ Las Raíces del Árbol Ranquel, una serie de doce micros-audiovisuales que abordan aspectos vinculados a la música, vestimenta, símbolos, festividades, creencias, cultura e identidad del pueblo ranquel;; el Foro de Educación Intercultural Bilingüe (EIB)-Santa Isabel, un registro audiovisual de conferencias que se desarrollaron en 2008 destinado a intercambiar experiencias para incluir a niños y jóvenes en el sistema educativo y enriquecer los procesos de enseñanza y aprendizaje mediante la reflexión sobre la identidad y la recuperación de las tradiciones. ${ }^{39}$

\section{A modo de cierre}

En distintos espacios se han producido importantes aportes al conocimiento y la enseñanza de la historia indígena regional y de los pueblos originarios en la actualidad. Sin embargo, hoy han cobrado inusitada vehemencia expresiones peyorativas, anacrónicas y falaces hacia los mapuches, catalogándolos de "indios chilenos invasores" que reclaman ilegítimamente derechos como ciudadanos argentinos. Esas palabras también se traducen en actitudes y acciones políticas estatales que son muy preocupantes. La "academia", en tanto productora y formadora de saberes, debe deconstruir esas narrativas nacionalistas e involucrarse en acciones destinadas a traspasar el reducto universitariopara que la renovación historiográfica esté presente en las aulas y en la comunidad. La tradición educativa de Argentina, al igual que en otros países latinoamericanos, ha jerarquizado la historia nacional por sobre otras historias y, a la par, ha construido un discurso de subyugación, menosprecio y discriminación hacia el indígena que es difícil desmontar porque esas representaciones se han reproducido extensamente en el ámbito escolar. Por esa razón, es necesario revisar los diseños curriculares, la formación docente y el proceso de enseñanza-aprendizaje.

Gabriel Villalón Gálvez y Joan Pagés Blanch (2015) plantearon que el lugar que ocupan los indígenas en el currículo es una consecuencia del lugar que ocupan en la sociedad ${ }^{40}$ y se preguntaron: ¿qué relación debería existir entre la historia nacional hoy, en vigor en la mayor parte de los países del mundo, y la historia de aquellos colectivos -como los indígenas- que además de marginados han sido ignorados en los textos? Al mismo tiempo, cuando se explicitan en los contenidos es necesario indagar qué discursos se construyen sobre estos actores y qué sucede en la práctica docente, un aspecto que ha sido menos estudiado y es necesario considerar (Lewkowicz y Rodríguez, 2015).

Mario Carretero (2007) señaló que los relatos históricos sobre el pasado son de tres tipos: a) los que se aprenden en los currículos escolares; b) la historia cotidiana que se presenta como un componente de la memoria colectiva que
35. El estudio de la lengua ranquel se remonta a 1983 , cuando la Subsecretaría de Cultura provincial encomendó esa tarea a la especialista en lingüística indígena Ana Fernández Garay, docente-investigadora en la UNLPam y UBA. Entre 2010 y 2012, en el marco del Proyecto de Extensión Universitaria Lengua ranquel, patrimonio de la provincia de La Pampa se elaboró un manual de ranquel, materiales didácticos y se asesoró a docentes ranquelinos.

36. Disponible en Internet: http:// www.lapampa.gov.ar/los-primerospintores-pampeanos.html

37. Es una co-producción con la Fundación Naturalia que se concretó en 1999. Disponible en Internet: https://rep.lapampa.edu.ar/index. $\mathrm{php} / \mathrm{material-audiovisual/item/his-}$ toria-1-arqueologia-y-poblamientoindigena?category_id=69

38. Disponible en Internet: https:// rep.lapampa.edu.ar/index.php/ material-audiovisual/category/lasraices-del-arbol-ranquel

39. Disponible en Internet: https:// rep.lapampa.edu.ar/index.php/ material-audiovisual/category/ conferencias-foro-eib-santa-isabel

40. Estos autores sostienen que para el caso chileno las representaciones que se construyen asocian a los indígenas con el proceso de mestizaje y, en un segundo relato, los muestra como guerreros, belicosos y rebeldes. 
articula los recuerdos y los relatos de una sociedad o grupo humano, constituyendo una serie de valores y creencias que les otorgan identidad; y c) la historia académica que se refiere a la ciencia que desarrollan los investigadores. Estas narraciones deben estar interrelacionadas, así la historia escolar se nutre de la investigación académica para construir sus contenidos y elaborar narraciones que luego serán utilizadas por los relatos cotidianos de la historia.

El desafío como educadores es ayudar a otros a pensar históricamente, acorde a la multiplicidad de actores, realidades y procesos sociales presentes. Esta labor es ineludible, cuánto más conciencia se adquiere sobre la construcción y la apropiación del conocimiento habrá más ciudadanos críticos, curiosos, reflexivos y, a la vez, sensibles a las necesidades de los "otros", que son parte constitutiva del "nosotros".

\section{Agradecimientos}

Agradecemos la invitación de las coordinadoras Lorena B. Rodríguez y Xochitl Inostroza Ponce a participar en la publicación de este dossier. También queremos agradecer la atenta lectura y las sugerencias pertinentes de los evaluadores anónimos. 


\section{Q Fuentes éditas citadas}

" AA.VV. (2002). Activa. La Pampa. Buenos Aires, Puerto de Palos.

"Diseño Curricular EGB 2. Versión Preliminar (1999). Ministerio de Cultura y Educación, Subsecretaría de Coordinación-Subsecretaría de Educación, Gobierno de la Provincia de La Pampa. Disponible en Internet: https://repositorio.lapampa.edu.ar/index.php/ disenos-anteriores. Consultado el 3 de agosto de 2016.

"Duval, M. (1941). Memoria. Periodo de Gobierno 1939-1940. Santa Rosa, Gobernación de La Pampa.

» Ley Nacional de Educación № 26.206 (2006). Ministerio de Educación, Ciencia y Tecnología de la República Argentina. Disponible en Internet: www.fmmeducacion.com. ar/Sisteduc/Leyes/ley26206_de_educ_nacional.doc. Consultado el 5 de mayo de 2016.

" Marcos de Referencia Educación Secundaria Orientada, Bachiller en Arte (2011). Consejo Federal de Educación. Disponible en Internet: http://www.me.gov.ar/consejo/ resoluciones/res11/142-11_arte.pdf. Consultado el 15 de agosto de 2016.

" Marcos de Referencia Educación Secundaria Orientada, Bachiller en Lengua (2011). Consejo Federal de Educación. Disponible en Internet:http://www.me.gov.ar/consejo/ resoluciones/res11/142-11_lenguas.pdf. Consultado el 15 de agosto de 2016.

» Marcos de Referencia Educación Secundaria Orientada, Bachiller en Turismo (2011). Consejo Federal de Educación. Disponible en Internet: http://www.me.gov.ar/consejo/ resoluciones/res11/156-11_01.pdf. Consultado el 15 de agosto de 2016.

» Materiales Curriculares Tercer Ciclo E.G.B. Ciencias Sociales (1997). Provincia de La Pampa, Ministerio de Cultura y Educación, Subsecretaria de Coordinación-Dirección General de Planeamiento. Disponible en Internet: https://repositorio.lapampa.edu. ar/index.php/disenos-anteriores/item/educacion-general-basica-tercer-ciclo-cienciassociales. Consultado el 22 de agosto de 2016.

" Materiales Curriculares para el Nivel Polimodal. Historia I y II (2001). Ministerio de Cultura y Educación de la Provincia de La Pampa. Dirección General de Educación Polimodal y Superior. Disponible en Internet: https://repositorio.lapampa.edu.ar/index. php/disenos-anteriores/item/historia-i-polimodalhttps://repositorio.lapampa.edu.ar/ index.php/disenos-anteriores/item/historia-ii-polimodal. Consultado el 22 de agosto de 2016.

» Materiales Curriculares para el primer, segundo y tercer año del Ciclo Básico de la Educación Secundaria: Historia (2009). Disponible en Internet: https://repositorio. lapampa.edu.ar/index.php/materiales/secundaria/basico. Consultado el 22 de agosto de 2016.

" Materiales Curriculares para el Ciclo Orientado de la Educación Secundaria: Antropología. Versión Preliminar (2013). Ministerio de Cultura y Educación, Gobierno de La Pampa. Disponible en Internet: https://repositorio.lapampa.edu.ar/index.php/ materiales/secundaria/orientado/item/antropologia. Consultado el 22 de agosto de 2016.

» Materiales Curriculares para el cuarto y quinto año del Ciclo Orientado de la Educación Secundaria: Historia (2013). Disponible en Internet: https://repositorio.lapampa.edu. ar/index.php/materiales/secundaria/orientado/item/historia-i-ii. Consultado el 22 de agosto de 2016.

" Materiales Curriculares para el sexto año del Ciclo Orientado de la Educación 
Secundaria: Historia (2013). Disponible en Internet: https://repositorio.lapampa.edu. ar/index.php/materiales/secundaria/orientado/item/historia-iii. Consultado el 22 de agosto de 2016.

» Materiales Curriculares para la Educación Primaria-Ciencias Sociales (2015). Disponible en Internet: https://repositorio.lapampa.edu.ar/index.php/materiales/primaria/item/ ciencias-sociales-primaria. Consultado el 22 de agosto de 2016.

» Mérega, H.; Pérez de Lois, G. y A. Celotto (2010). Historia. Las sociedades de América y Europa entre el siglo XIV y fines del siglo XVIII. Serie Saberes Clave. Buenos Aires, Santillana.

» Núcleos de Aprendizajes Prioritarios. Ciclo Básico Educación Secundaria $1^{\circ}$ y $2^{\circ} / 2^{\circ}$ y $3^{\circ}$ Años (2011). Ministerio de Educación de la Presidencia de la Nación-Consejo Federal de Educación. Disponible en Internet: https://repositorio.lapampa.edu.ar/index.php/nap/ secundaria. Consultado el 3 de agosto de 2016.

»Proyecto de Cambio en la Educación Media (1990). Lineamientos Curriculares. Provincia de La Pampa, Talleres Gráficos de la Imprenta Oficial de la Subsecretaría de Información Pública.

» Resolución Nº64/99 del Consejo Superior de la UNLPam. Modificación parcial del Plan de Estudios de la Carrera Licenciatura en Historia. Disponible en Internet:http:// actosresolutivos.unlpam.edu.ar/static_ecs/media/uploads/pdf/4_7_1999_64_11gVkgl. pdf. Consultado el 3 de marzo de 2016.

» Resolución Nº79/99 del Consejo Superior de la UNLPam. Modificación parcial del Plan de Estudios de la Carrera de Profesorado en Historia. Disponible en Internet:http:// actosresolutivos.unlpam.edu.ar/static_ecs/media/uploads/pdf/4_7_1999_79_5oln3G2. pdf. Consultado el 3 de marzo de 2016.

» Resolución N²28/o9 del Consejo Superior de la UNLPam. Plan de Estudio de la carrera Profesorado en Historia. Disponible en Internet: http://actosresolutivos.unlpam.edu. ar/static_ecs/media/uploads/pdf/4_7_2009_228_GgVDndE.pdf. Consultado el 3 de marzo de 2016.

» Resolución N 194/11 del Consejo Superior de la UNLPam. Plan de Estudio de la carrera Licenciatura en Historia. Disponible en Internet: http://actosresolutivos.unlpam.edu. ar/static_ecs/media/uploads/pdf/4_7_2011_194_PaTMyhx.pdf. Consultado el 3 de marzo de 2016.

»Resolución № 1272/12. Aprobación de la Estructura Curricular correspondiente a $4^{\circ}, 5^{\circ}$ y 6ำ Año del Ciclo Orientado de la Educación Secundaria. Boletín Oficial de la Provincia de La Pampa № 3014. Disponible en Internet: http://www.lapampa.gov.ar/images/ stories/Archivos/Bof/2012/PDF/Sep3014.pdfConsultado el 3 de marzo de 2016.

» Revista Gloriosa Nación. Ilustración Argentina de Actualidades. Edición especial referida al Territorio Nacional de La Pampa (1942). Buenos Aires.

» Stieben, E. (1940). El pasado y el Presente de La Pampa. Cinco conferencias radiales. Publicación dispuesta por el Gobernador Duval como suplemento de la Memoria Gubernativa correspondiente al año 1939. Santa Rosa, Gobernación de La Pampa.

» Stieben, E. (1946). La Pampa. Su realidad, su geografía y su porvenir. Buenos Aires, Ediciones Peuser. 


\section{Q Bibliografía citada}

" Altube, M. I. (1999). “Mujeres en 'tierra adentro'. Las cautivas en las sociedades indígenas de la región pampeana y norpatagónica (siglos XVIII y XIX)" en Villar, D.; Di Liscia M. H. y M. J. Caviglia (eds.), Seis estudios sobre la condición femenina: 89-120. Buenos Aires, Biblos/ Departamento de Humanidades, Universidad Nacional del SurFacultad de Ciencias Humanas, Universidad Nacional de La Pampa.

"Aman, R. (2010). El indígena "latinoamericano" en la enseñanza: Representación de la comunidad indígena en manuales escolares europeos y latinoamericanos. Estudios Pedagógicos XXXVI (2): 41-50.

» Argeri, M. E. (2005). De guerreros a delincuentes. La desarticulación de las jefaturas indígenas y el poder judicial. Norpatagonia, 1880-1930. Madrid, Consejo Superior de Investigaciones Científicas.

" Benítez, N., Diez, V. y M. Marini de Díaz Zorita (1986). La Pampa Total. Aspectos históricos. Santa Rosa, Ministerio de Cultura de la Provincia de La Pampa.

" Berón, M. (2009). “Arqueología de los Departamentos Curacó y Lihuel Calel. Una historia de cazadores" en Salomón Tarquini, C.; Laguarday P. y C. Kuz, (eds.), Puelches. Una historia que fluye junto al Salado: 21-38. General Acha, EdUNLPam.

" Billorou, M. J. y L. Sánchez (2011). “La Pampa: por el camino de la educación” en Lluch, A. y M. S. Di Liscia (eds.), Historia de La Pampa II. Sociedad, política y economía de la crisis del treinta al inicio de un nuevo siglo: 131-149. Santa Rosa, EdUNLPam.

»Carretero, M. (2007). Documentos de identidad: la construcción de la memoria histórica en un mundo global. Buenos Aires, Paidós.

»Delrio, W. (2005). Memorias de expropiación. Sometimiento e incorporación indígena en la Patagonia 1872-1943. Bernal, Universidad Nacional de Quilmes.

»Delrio, W. (2012). Entrar y salir de la Etnohistoria. Memoria Americana 20 (1): 147-171. Disponible en Internet: http://ppct.caicyt.gov.ar/index.php/memoria-americana/ article/view/1970/1669. Consultado el 5 de junio de 2017.

"Depetris, J. C. (2003). Gente de la Tierra. Los que sobrevivieron a la conquista, con nombre y apellido. Censo de 1895. Pampa Central. Santa Rosa, Ediciones de la Travesía.

»Depetris, J. C. (2009). "Silvano Pincén, un ícono en la memoria local" en Crochetti, S. y M. Lanzillotta (eds.), Anguil 1906-2006. Senderos que cuentan historias: 15-21. Santa Rosa, EdUNLPam.

"Depetris, J. C. y P. Vigne (2000). Los Rostros de la Tierra. Iconografía indígena de La Pampa. 1870-1950. Santa Rosa, Amerindia/ Universidad Nacional de Quilmes.

" Di Liscia, M. S. (1999). "Medicina, religión y género en la relación entre indígenas y blancos (Región Pampeana y Norpatagónica, Siglos XVIII y XIX)" en Villar, D.; Di Liscia M. H. y M. J. Caviglia (eds.), Historia y género. Seis estudios sobre la condición femenina: 53-87. Buenos Aires, Biblos.

» Di Liscia, M. S. (2002a). “Viruela, vacunación e indígenas en la Pampa Argentina del siglo XIX” en Armus, D. (ed.), Entre médicos y curanderos. Cultura, historia y enfermedad en la América Latina moderna: 29-69. Buenos Aires/ Barcelona, Grupo Editorial Norma.

"Di Liscia, M. S. (2002b). Prácticas médicas, prácticas políticas. Rosas y la vacuna indígena. Revista de Historia Social y de las Mentalidades 6: 143-159. 
» Di Liscia, M. S. y M. Zink (1995). “Mujeres indígenas de la región pampeana (siglos XVIII Y XIX). Estado actual del tema y avances en la investigación” en Tamagnini, M. (comp.), Actas de las Segundas Jornadas de Investigadores en Arqueología y Etnohistoria del CentroOeste del País: 173-183. Río Cuarto, Universidad Nacional de Río Cuarto.

»Dussel, E. (1992). El encubrimiento del otro. La Paz, Plural.

» Fernández Garay, A.; Aguirre, D. y C. Montecino (2016). La extensión al servicio de la enseñanza del ranquel. Cuadernos de Extensión Universitaria de la UNLPam 2: 58-79. Santa Rosa, EdUNLPam. Disponible en Internet: http://www.unlpam.edu.ar/cultura-y extension/edunlpam/catalogo/publicaciones-de-extension-universitaria/cuadernosde-extension-universitaria-de-la-unlpam-n-2. Consultado el 3 de marzo de 2017.

» Lewkowicz, M. (2015). La resistencia de los pueblos indígenas a la conquista española en los libros de texto para las escuelas primarias en Argentina. Espacio, Tiempo y Educación, 2 (1): 121-139. Disponible en Internet: http://www.espaciotiempoyeducacion.com/ojs/ index.php/ete/article/view/23. DOI: http://dx.doi.org/10.14516/ete.2015.002.001.007. Consultado el 3 de marzo de 2017.

» Lewkowicz, M. y M. Rodríguez (2015). Las sociedades aborígenes en los textos escolares: de "indios salvajes" a "pueblos originarios". Una mirada en la larga duración. Clío $\varepsilon$ Asociados 20-21: 116-137. Disponible en Internet: http://www.clio.fahce.unlp.edu.ar/ article/view/Clion20aog/8187. Consultado el 3 de marzo de 2016.

»Lluch, A. (2002). Un largo proceso de exclusión. La política oficial y el destino final de los indígenas ranquelinos en La Pampa (Argentina) a través de un estudio de caso. Quinto Sol 6: 43-68.

» Mandrini, R. (2007). La historiografía argentina, los pueblos originarios y la incomodidad de los historiadores. Quinto Sol 11: 19-38. Disponible en Internet: http://cerac.unlpam. edu.ar/index.php/quintosol/article/view/718. Consultado el 3 de septiembre de 2016.

» Mases, E. (2002). Estado y cuestión indígena. El destino final de los indios sometidos en el sur del territorio (1878-1910). Buenos Aires, Prometeo/ Entrepasados.

» Nagy, M. (2013). Una educación para el desierto argentino. Los pueblos indígenas en los planes de estudio y en los textos escolares actuales. Espacios en blanco. Serie Indagaciones. 23 (2): 187-223. Disponible en Internet: http://www.scielo.org.ar/scielo. php?script=sci_arttext\&pid=S1515-94852013000200001. Consultado el 3 de marzo de 2016.

» Poduje, M. I. (comp.) (1998). Memorias de las Jornadas Ranquelinas. Santa Rosa, Subsecretaría de Cultura de La Pampa.

»Poduje, M. I. (comp.) (2001). Presencia ranquelina. Santa Rosa, Gobierno de La Pampa.

»Pousa Castelo, M. (2013). Los indígenas en la enseñanza de las Ciencias Sociales en España. Silenciamiento, burlas y romanticismo. Clío \& Asociados. La historia enseñada 17: 162-191.

»Quijano, A. (2000). “Colonialidad del poder, eurocentrismo y América Latina” en Lander, E. (ed.), Colonialidad del Saber, Eurocentrismo y Ciencias Sociales: 201-246. Buenos Aires, CLACSO-UNESCO.

" Rollhauser, E. (2011). “Pueblos originarios en la zona central pampeana (siglos XVIII al XX)” en Annecchini, M.; Blanco, D.; Lorini, A y E. Rollhauser (eds.), En la remota orilla del recuerdo. Eduardo Castex 1908-2008: 33-68. La Pampa, Municipalidad de Eduardo Castex.

» Salomón Tarquini, C. (2001). Redes de rescate de cautivos: una modalidad de articulación de las relaciones interétnicas en región pampeana (1870-1880). Quinto Sol 5: 89-112.

»Salomón Tarquini, C. (2006). “El niño que hablaba con el papel. Santiago Avendaño” en 
Mandrini, R. (ed.), Vivir entre dos mundos. Las fronteras del sur de la Argentina. Siglos XVIII y XIX: 119-136.Buenos Aires, Taurus.

»Salomón Tarquini, C. (2010). Largas noches en La Pampa. Itinerarios y resistencias de la población indígena (1878-1976). Buenos Aires, Prometeo.

»Salomón Tarquini, C. (2014). “El repoblamiento indígena: 1880-1950” en Lluch, A. y C. Salomón Tarquini (eds.), Historia de La Pampa. Sociedad, política, economía, desde los poblamientos iniciales hasta la provincialización (ca.80oo a 1952): 87-100. Santa Rosa, EdUNLPam. (Segunda edición corregida y ampliada).

»Salomón Tarquini, C. (2015). “Investigaciones socio-históricas relativas a pueblos indígenas en el IESH (UNLPam): historia, problemas y perspectivas” en Salomón Tarquini, C. e I. Roca (eds.), Investigaciones acerca de y con el pueblo ranquel: pasado, presente y perspectivas. Actas de las Jornadas en Homenaje a Germán Canuhé: 111-124. Santa Rosa, EdUNLPam.

»Salomón Tarquini, C. y A. Abbona (2010). “Tenencia y uso de la tierra de las poblaciones indígenas en el oeste de La Pampa (primera mitad del siglo XX)” en Lluch, A. y M. Moroni (comps.), Tierra Adentro... Instituciones económicas y sociales en los Territorios Nacionales (1884-1951): 63-88. Rosario, Prohistoria.

»Salomón Tarquini, C. y R. Casali (2015). Los pueblos indígenas de Pampa y Patagonia, siglo XVIII-XX. Un breve estado de las investigaciones. Papeles de Trabajo 9 (16): 22-55.

»Salomón Tarquini, C. y M. del Río (2014). “Pueblos originarios: de la ocupación territorial de Pincén a la comunidad “Eusebia Farías”” en Pittaluga, R; Sánchez, N. y M. J. Billorou (eds.), Miguel Riglos, a uno y otro lado de las vías: 29-42. Santa Rosa, EdUNLPam.

»Salomón Tarquini, C. y B. Dillon (2011). “Un espacio entre varios mundos: los ranqueles, Carri-loo y El Recado en el MamüllMapu” en Sánchez, L y S. Cornelis (eds.), Transitar las corrientes de la memoria. Caleufú 1911-2011: 19-30. Santa Rosa, EdUNLPam.

» Salomón Tarquini, C. y M. Zink (2004). “Memoria e historia: genocidio y etnocidio en textos académicos y escolares sobre sociedades indígenas de la región pampeana" en Boulgourdjian-Toufeksian, N.; Toufeksian J. C. y C. Alemian (eds.), Análisis de prácticas genocidas. Actas del IV Encuentro sobre Genocidio: 261-28o. Buenos Aires, Fundación Siranoush \& Boghos Arzoumanian.

»Salomón Tarquini, C. y M. Zink (2008). “De vivir en la 'tierra de la libertad' a 'andar como ladrones en los campos que eran nuestros'. La ocupación indígena de la zona de Guatraché durante el siglo XIX" en Rodríguez, A. M. T.; Doba, C.; Moroni, M.; Fernández, E.; Folmery, D y G. Herzel (eds.), Esta antigua tierra que somos. Guatraché 1908-2008: 4558. Buenos Aires, Miño y Dávila.

»Salomón Tarquini, C. y M. Zink (2009). “Las tierras del indómito cacique” en Crochetti, S. y M. Lanzillotta (eds.), Anguil 1906-2006. Senderos que cuentan historias: 3-13. Santa Rosa, EdUNLPam.

»Villalón Gálvez, G. y J. Pagés Blanch (2015). La representación de los y las indígenas en la enseñanza de la historia en la educación básica chilena. El caso de los textos de estudio de la historia de Chile. Dialogo andino 47: 27-36.

»Villar, D. (1997). Aindiados, indígenas y política en la frontera bonaerense (1827-1830). Quinto Sol 1: 103-144.

»Villar, D. (ed.) (1998). Relaciones inter-étnicas en el Sur bonaerense 1810-1830. Bahía Blanca, UNS-UNLPam-UNCPBA.

» Villar, D. y M. Zink (1998). Madres, Padres, Hijos. Etapas vitales en el proceso de enculturación de niños y jóvenes en las sociedades indígenas de la región pampeanonordpatagónica. La Aljaba. Segunda Época III: 132-154. Disponible en Internet: http:// 
www.biblioteca.unlpam.edu.ar/pubpdf/aljaba/vozao8villar.pdf. Consultado el 3 de febrero de 2016.

»Villar, D. (ed.) (2003). Conflicto, poder y justicia en la frontera bonaerense, 1818-1832. Bahía Blanca-Santa Rosa, UNSur-UNLPam.

»Zink, M. (2002). "Las sociedades indígenas regionales y su vinculación con Salinas Grandes” en Crochetti, S. (ed.), Historias de un lugar en La Pampa: Macachín y su gente:13-34. La Pampa, Municipalidad de Macachín.

»Zink, M. (2014). “El poblamiento inicial de La Pampa según los principales sitios arqueológicos” en Lluch, A. y C. Salomón Tarquini (eds.), Historia de La Pampa. Sociedad, política, economía, desde los poblamientos iniciales hasta la provincialización (ca.8000 a 1952): 29-47. Santa Rosa, EdUNLPam. (Segunda edición corregida y ampliada).

»Zink, M. y V. Günther (2011). “Miles de años antes” en Zink, M. y M. Moroni, (eds.), Tierra fría... que se ha vuelto abrigo:23-39. Buenos Aires, Miño y Dávila.

»Zink, M. y C. Salomón Tarquini (2014). “Las sociedades indígenas y las relaciones sociales en espacios de frontera” en Lluch, A. y C. Salomón Tarquini, (eds.), Historia de La Pampa. Sociedad, política, economía, desde los poblamientos iniciales hasta la provincialización (ca. 8000 a 1952): 49-86. Santa Rosa, EdUNLPam. (Segunda edición corregida y ampliada). 